\title{
A avaliação em foco: o que provam as provas de Língua Portuguesa e de Redaçao do exame vestibular?*
}

\author{
Exams of Portuguese Language and Writing \\ in entrance examinations: what do they \\ prove?
}

Regina Lúcia Péret Dell'Isola**

Universidade Federal de Minas Gerais

\begin{abstract}
RESUMO: As provas de Língua Portuguesa e de Redação dos vestibulares são instrumentos voltados para a seleção de candidatos aptos para ingressar no Ensino Superior. Espera-se que eles demonstrem ter conhecimentos linguísticos e textuais que lhes permitam interpretar e produzir textos da esfera acadêmica. Mas, essas provas evidenciam os conhecimentos necessários para a admissão dos melhores candidatos nos cursos de graduação? Com o objetivo de responder a essa pergunta, analisamos questôes propostas em vestibulares da UFMG nos últimos dez anos. Constatamos que, entre 2000 e 2009, avaliam-se competências a serem demonstradas por meio de habilidades, como localizar informaçóes explícitas, inferir as implícitas em um texto, reconhecer novos sentidos atribuídos às palavras dentro de uma produção textual. Constatamos também a presença de diversos gêneros textuais da mídia impressa que favorece a reflexão crítica, o exercício de formas de pensamento mais elaboradas. Concluímos que as provas desse concurso cumprem a meta a que se destinam.
\end{abstract}

PALAVRAS-CHAVE: Gênero textual, exame vestibular, leitura, redação.

ABSTRACT: Exams of Portuguese Language and Writing in entrance examinations are instruments aiming at the selection of the candidates who are fit to start undergraduate studies. It is expected that they show the textual and linguistic knowledge that allow them to interpret and produce texts in the academic field. But do these texts elicit the necessary knowledge for the admission of the best candidates to undergraduate courses? With the purpose of answering this question we have analyzed the questions asked in the entrance examinations of UFMG in the last 10 years. We have found that, between the years 2000 and

\footnotetext{
* Este trabalho contou com o apoio da FAPEMIG (Fundação de Amparo à Pesquisa do Estado de Minas Gerais).

** reginadellisola@gmail.com
} 
2009, the competence is assessed through skills such as locating explicit information, deducing implicit information, recognizing new meanings of words, within a given text. We have also verified the presence of several text genres from press media which favor critical reflection, and the application of more elaborated forms of reasoning. We have concluded that these tests fulfill their intended goal.

KEYWORDS: Academic genre; entrance examination; reading; writing.

\section{Palavras iniciais}

O processo de formação acadêmica requer do estudante habilidades práticas no uso da língua. No âmbito universitário, a difusão de conhecimentos e de informaçôes é feita por meio de gêneros, orais ou escritos, como aulas, seminários, palestras e congressos, predominantemente na variedade padrão da língua portuguesa. Para ingressar nesse ambiente, é preciso que se comprove domínio do idioma e capacidade de compreensão textual e produção escrita.

No Brasil, os concursos vestibulares são instrumentos voltados para a seleção de candidatos que demonstrem ter conhecimentos linguísticos e textuais que lhes permitam interpretar e produzir textos da esfera acadêmica. Assim, espera-se que nesse exame, a avaliação nas provas de Língua Portuguesa e de Redação coloque em evidência os conhecimentos necessários para a admissão dos candidatos nos cursos de graduação. Mas, o que provam essas provas?

Com o objetivo de responder a essa pergunta, analisamos propostas de questões de provas de Língua Portuguesa e de Redação, aplicadas no período de 2000 a 2009, em vestibulares da UFMG. Nossa pesquisa partiu da observação dos gêneros textuais apresentados para leitura e, em seguida, para a verificação do tipo de questão de interpretação e / ou produção escrita e sua relevância para a finalidade da seleção dos candidatos.

Neste artigo, apresentamos breve análise da constituição das questôes das provas Língua Portuguesa e de Redação do Vestibular da Universidade Federal de Minas Gerais (UFMG) na última década, a fim de analisar a qualidade de avaliação em expressão e compreensão textuais a que os candidatos foram submetidos nesses últimos anos. Conforme aponta Xavier (2007), a UFMG, sendo uma das mais expressivas instituições de Ensino Superior do país, tem demarcado, ao longo dos anos, importantes tendências de exploração da escrita. Inicialmente, apresentaremos o perfil das provas de múltipla escolha e, em seguida, demonstraremos a variedade de gêneros presentes nas provas de Redação, o que demonstra que essa é uma avaliação de habilidade de leitura e 
de expressão verbal, para, finalmente, aferir o que provam essas provas nos últimos anos.

\section{Duas etapas de um processo}

O vestibular da UFMG realiza-se, uma vez ao ano, em duas etapas. A primeira etapa compreende provas de múltipla escolha aplicadas em um único dia. A segunda etapa destina-se apenas aos aprovados na etapa anterior e compreende uma prova de Redação para todos os candidatos e provas específicas, de acordo com a área do curso pretendido. Sendo um concurso público de larga dimensão, esse Vestibular envolve um grande número de estudantes egressos do Ensino Médio, de diversas regiōes de Minas Gerais e de outros Estados da Federação. Dessa forma, é necessário o estabelecimento de regras claras e igualmente válidas para todos.

Um dos instrumentos de que se dispõe para aferir as habilidades de leitura dos candidatos é a prova de múltipla escolha, que impõe aos concorrentes a contingência de localizar a alternativa correta num grupo de quatro opções e viabiliza a correção de um grande número de provas de forma objetiva e rápida. Outro instrumento é a prova de Redação, que afere as habilidades de leitura e escrita dos candidatos. $\mathrm{Na} 1^{a}$ etapa, espera-se que o candidato demonstre várias habilidades de leitura e, na $2^{\mathrm{a}}$ etapa, espera-se que ele revele, ainda, pela redação, seu desempenho em produção textual, suas habilidades de uso da variante padrão, bem como sua capacidade de compreensão, raciocínio, pensamento crítico, análise e síntese.

As orientações que constam da Resolução do Conselho de Ensino, Pesquisa e Extensão (CEPE) estabelecem as normas para o Vestibular da UFMG:

As provas e os testes serão elaborados de acordo com os programas constantes do Edital publicado no Diário Oficial de Minas Gerais, destinando-se a avaliar conhecimentos e habilidades do candidato, verificando sua capacidade de raciocínio, pensamento crítico, compreensão, análise e síntese (Art. $1^{\circ}$, item 1.4).

Nesse processo, não é novidade que as provas de Língua Portuguesa e de Literatura Brasileira sejam instrumento para selecionar os candidatos que demonstrem possuir conhecimentos linguísticos e textuais que lhes permitam interpretar e produzir textos. Em nossa pesquisa, analisamos o foco das questôes dessas provas, ou seja, buscamos evidências que sinalizam serem, de fato, provas que avaliam os conhecimentos necessários a serem evidenciados 
pelo candidato de modo a aprová-lo por levarem-no a demonstrar que está apto a acompanhar um curso de nível superior.

De acordo com Nascimento e Costa Val (1999), a expectativa social quanto ao uso da língua nas instâncias de formação e exercício dos profissionais de curso universitário deriva de uma práxis social e historicamente estabelecida. Os textos que os alunos das diferentes áreas da ciência e das artes deverão ler estão escritos no dialeto de prestígio, socialmente legitimado, a que se costuma chamar português padrão. A expectativa dos professores, dos colegas e das pessoas com quem esses alunos deverão interagir no exercício profissional é de que os textos escritos por eles sejam produzidos nesse dialeto padrão. No âmbito universitário, mesmo a difusão oral de conhecimentos e informações, nas aulas, seminários, palestras, congressos, se faz numa modalidade de língua falada que apresenta recortes de seleção vocabular e de traços morfossintáticos nem sempre coincidentes com os da fala cotidiana dos vários setores da população. Comecemos com as provas da primeira etapa desse concurso.

\section{Múltiplas escolhas ou única escolha?}

As provas de múltipla escolha de língua portuguesa e de literatura brasileira (LPLB) da UFMG apresentam um ou mais textos escritos para leitura, seguidos de questôes sobre esses textos e de questóes sobre as obras literárias indicadas previamente. Os textos - verbais em sua quase totalidade - são unidades linguísticas entre interlocutores: autor e leitor em que se instaura um espaço de ação entre sujeitos em que se exercitam e se desenvolvem as habilidades de compreensão, raciocínio, pensamento crítico, bem como as capacidades de análise e síntese. Como se avalia a qualidade da leitura do candidato?

Nessas provas de múltipla escolha, procura-se avaliar competências básicas que devem ser demonstradas por meio de habilidades, como localizar informaçóes explícitas, inferir as implícitas em um texto, reconhecer novos sentidos atribuídos às palavras dentro de uma produção textual, distinguir o que é conotativo e simbólico do que é denotativo e literal. Assim, não se espera que sejam identificadas apenas a ideia apresentada na superfície do texto mas também as ideias que ficam nas entrelinhas. A tarefa do leitor competente é, portanto, apreender o sentido do texto.

O QUADRO 1, a seguir, apresenta a fonte de cada texto para leitura dos vestibulares de 2000 a 2009, seguido da data de publicação e da classificação por gênero de cada texto selecionado. 
QUADRO 1

As fontes e os gêneros dos textos para a leitura nos últimos Vestibulares da UFMG

\begin{tabular}{|c|c|c|c|}
\hline Ano & Fonte do texto & $\begin{array}{l}\text { Data da } \\
\text { publicação }\end{array}$ & Gênero \\
\hline & $\begin{array}{l}\text { SOUZA, J. A vingança da miséria. } \\
\text { Folha de São Paulo. Caderno Opiniāo, p.2. }\end{array}$ & 31 out. 1994. & Artigo de Opinião \\
\hline 2000 & $\begin{array}{l}\text { ARBEX JR, J. Quem escreve com as mãos? } \\
\text { Caros amigos, São Paulo, n.25, p.8-9. }\end{array}$ & Abr.1999. & Artigo de Opinião \\
\hline & $\begin{array}{l}\text { TOLEDO, J. Roberto de . Globalização } \\
\text { aprofunda o abismo entre ricos e pobres. } \\
\text { Folha de S.Paulo. Caderno Especial, p. } 12\end{array}$ & 2 nov. 1997. & Notícia \\
\hline 2001 & TEIXEIRA, Ivan. VEJA, São Paulo, p.148-149. & 21 abr.1999 & Artigo de Opinião \\
\hline & $\begin{array}{l}\text { SANTOS, Jorge Fernando dos. Estado de Minas, } \\
\text { Belo Horizonte. }\end{array}$ & 10 jun. 1996. & Artigo de Opinião \\
\hline 2002 & $\begin{array}{l}\text { LACERDA, G. O Globo. Rio de Janeiro, } \\
\text { Opinião, p. } 7\end{array}$ & 19 abr. 2001. & Artigo de Opinião \\
\hline 2003 & TABAK, I. Jornal do Brasil. Rio de Janeiro. p.12. & 13 ago. 2000 & Entrevista \\
\hline 2004 & $\begin{array}{l}\text { WANDELLI, Raquel. Entre pergaminhos } \\
\text { humanos e bits eletrônicos: o livro na era do } \\
\text { computador. http://www.escritoriodolivro.org.br }\end{array}$ & Maio 2003. & Reportagem \\
\hline 2005 & $\begin{array}{l}\text { CARNEIRO, H. Não sabemos o que comemos. } \\
\text { Ciência Hoje, v. } 34 \text {, n. 203, p 40-42 }\end{array}$ & Abr. 2004. & $\begin{array}{l}\text { Artigo de divul- } \\
\text { gação científica }\end{array}$ \\
\hline 2006 & $\begin{array}{l}\text { KANITZ, Stephen. Ponto de Vista. VEJA, } \\
\text { Rio de Janeiro, p. } 22 \text {. }\end{array}$ & 29 set. 2004 . & Artigo de Opinião \\
\hline 2007 & $\begin{array}{l}\text { BETTO, Frei. Estado de Minas, Belo } \\
\text { Horizonte. Caderno Cultura, p. } 10 .\end{array}$ & 8 jun. 2006. & Artigo de Opinião \\
\hline 2008 & ARAÚJO, Alcione. ISTOÉ MINAS. p. 34. & 26 fev. 1992. & Ensaio \\
\hline 2009 & $\begin{array}{l}\text { CONY, Carlos Heitor. Folha online. } \\
\text { SIEGEL, Lee. Trecho. Estado de S. Paulo } \\
\text { Teoria e Debate, n. } 74\end{array}$ & $\begin{array}{l}12 \text { jan. } 2005 . \\
2 \text { mar. } 2008 . \\
\text { nov./dez. } 2007\end{array}$ & $\begin{array}{l}\text { Artigo de Opinião } \\
\text { Entrevista } \\
\text { Artigo de Opinião }\end{array}$ \\
\hline
\end{tabular}

Constatamos haver, nos últimos dez anos, diversidade das fontes - todas da mídia impressa de grande circulação nacional - e a preferência pelo gênero artigo de opinião. Dos quinze textos das provas, nove são argumentativos. Observamos que não há uma relação entre o ano do concurso vestibular e a data da publicação do texto escolhido. Verifica-se, nos anos 2000, 2002, 2004, 
2005, 2007 e 2009, a escolha de texto publicado no ano de elaboração da prova. Entretanto, isso não é uma regra. Levanta-se aqui a hipótese de que não é relevante a data da publicação, e sim a qualidade do texto selecionado.

Para a leitura, são privilegiados textos da mídia impressa que, por suas características e usos, podem favorecer a reflexão crítica, o exercício de formas de pensamento mais elaboradas. A partir de temas atuais, selecionaram-se textos que buscam um candidato que demonstre conhecimento da realidade social brasileira, que demonstre compreender o significado da participação social e da cidadania. Por isso, gêneros como notícias, editoriais, artigos de opinião, entrevistas e outros em que se predomina o modo argumentativo de produção discursiva são os mais frequentes.

Ao analisarmos as questôes de múltipla escolha das provas de Português, constatamos que, nesses anos, foram exigidos dos candidatos ao vestibular da UFMG, a capacidade de interpretar o texto; identificar a ideia central do texto, escolhendo, para isso, o título a ele mais adequado; compreender as ideias defendidas pelo locutor ou o objetivo principal do texto; inferir a partir de informações veiculadas no texto; identificar estratégias e recursos de construção textual; compreender argumentos apresentados no texto; reconhecer informações veiculadas no texto; avaliar termo de mesma forma com funções distintas; relacionar enunciados; reconhecer sinônimos; perceber como se dá a elaboração dos argumentos; reconhecer estrutura de composição e construção textual; dominar vocabulário e redes semânticas; estabelecer relações entre as partes de um enunciado; parafrasear trechos extraídos do texto; examinar oposiçóes semânticas entre termos.

Com base nessa análise, concluímos que as questóes de múltipla escolha da prova de Português exploram a identificação de informações textuais, a articulação de informações internas e externas ao texto, a realização de antecipações e de inferências, a validação de inferências autorizadas e invalidaçãoo de inferências não-autorizadas, a apropriação das características do gênero, a mobilização de esquemas cognitivos, a ativação de conhecimentos prévios partilhados e relevantes ao contexto e a ativação de conhecimentos linguísticos para se perceber os sentidos textuais (implícitos ou explícitos), as intençóes e os recursos utilizados pelo autor para significar e atuar verbalmente. Além disso, verificamos que algumas questões de língua portuguesa focalizaram a capacidade de reflexão do candidato acerca de aspectos da variação linguística e do conhecimento de algumas construções mais utilizadas do português padrão. 
Destacam-se questôes que avaliam o candidato quanto à percepção do posicionamento do autor em relação ao tema; a capacidade de preencher adequadamente lacunas do texto; comparar textos sobre o mesmo tema; perceber o sentido gerado a partir do uso de determinada forma linguística; a habilidade de identificar argumentos usados para defender uma posição, de perceber contradiçóes e os diferentes posicionamentos das vozes presentes em um texto ou de autores de diferentes textos e de comprovar a leitura das obras de literatura brasileira indicadas.

Observados os objetivos subjacentes a essas provas analisadas, conclui-se que as questôes de múltipla escolha foram propostas para testar, principalmente, as habilidades de compreensão e de raciocínio dos candidatos. Evidenciou-se, nesta pesquisa, que são evitadas questôes em que se exigem análises de palavras e frases descontextualizadas, assim como de questóes que envolvam identificação e classificação de formas linguísticas, segundo teorias gramaticais, e de questóes baseadas, sobretudo, em memorização e em reconhecimento.

\section{A leitura de obras literárias}

Considerada a importância do papel formador dos textos literários na educação dos jovens, nos concursos vestibulares têm-se indicado obras de referência para serem lidas previamente ao processo seletivo. Segundo Miranda et alli (2009), os textos literários póem em pauta o uso e o exercício disciplinado da imaginação. Obras de arte resultam da atividade livre do espírito, são criações puras, sempre lançam mão do recurso à fantasia e à imaginação. A faculdade de lidar de modo disciplinado com a imaginação é muito importante para toda atividade criadora e transformadora do mundo. Inegavelmente, é essencial ao desenvolvimento de todas as áreas do conhecimento que os cientistas tenham imaginação bem desenvolvida.

As questôes relativas às obras literárias visam à comprovação de que os candidatos leram os livros indicados. Nesses anos foram indicados aproximadamente cinco livros diferentes para cada concurso, num total de cinquenta obras literárias indicadas entre 2000 a 2009. Verifica-se que nesses anos avaliou-se a capacidade dos candidatos de se envolverem pertinentemente com a literatura; de compreenderem o contexto sociohistórico em que ocorrem os fatos narrados; de perceberem situações de interlocução; de relacionarem textos com seus autores, com outros textos, com seus conhecimentos prévios, de inferirem significações não-explícitas e de aplicarem conhecimentos necessários na identificação da resposta correta em questôes de múltipla escolha. Conforme aponta Oliveira (2008), 
o vestibular da UFMG, ao mesmo tempo em que revigora a manutenção de certo cânone literário, baseado na nossa rica tradição cultural ocidental, também investe na abertura para a expressão de culturas minoritárias do Brasil, através de obras não-canônicas, ou que foram canonizadas em outros espaços, tais como Quarto de despejo, indicada para a seleção do Vestibular 2001 da UFMG, consagrada pelo leitor comum, não especializado na recepção do texto literário, mas que, por sua vez, estabelece a primeira canonização dessa obra, já que canonização significa aplauso da obra através de sua leitura, tornando-a sucesso de um público leitor, especializado ou não. A indicação pela UFMG, dessa e de outras obras literárias, descentradas do cânone da tradição, para o vestibular, pareceu-nos relevante para que pudéssemos discutir a respeito da existência de vários centros culturais e não de um único centro hegemônico (Disponível em: <http://www.letras.ufmg.br/ atelaeotexto/pesquisaleni.htm $>$. Acesso em: ....)

A autora considera obra canônica como sendo aquela que está inserida em uma determinada tradição cultural, tipicamente ocidental. Mesmo quando a obra contesta essa tradição, ela rompe com o passado recente e restaura o passado remoto de tal forma que a retomada da tradição está sempre em pauta. Resgatar a tradição implica apropriar-se dela para revigorá-la ou para negá-la.

Concluímos, com Oliveira (2008), a partir da análise do nosso corpus, que é prática dessa universidade, nos últimos anos, a de incluir obras novas, descentralizando, dessa forma, os parâmetros de canonização na literatura, ou criando outros. Verifica-se uma tendência à diversificação, sem excluir o cânone, sem recusar experiências das margens, sem eleger uma única tradição hegemônica como se ela fosse a única representante de um país tão extenso quanto o Brasil. Valorizam-se grupos que também têm direito de serem ouvidos e terem sua cultura valorizada.

Para Oliveira (2008), o vestibular da UFMG constitui uma boa amostragem de exame que, ao mesmo tempo em que conserva certa tradição literária brasileira a renova, por meio da recorrência a obras consagradas e da inserção de obras menos conhecidas, no debate acadêmico.

Ao propiciar a leitura das obras pelos candidatos ao vestibular, o concurso da UFMG instiga a atividade da crítica literária especializada a estabelecer consideraçôes sobre elas, de forma a constituir-se como elemento inegável na manutenção da leitura literária e na formação do leitor na contemporaneidade. [...] Percebemos que o leitor de nível médio, hoje, manipula, no cotidiano, uma imensa variedade e quantidade de informação, inclusive aquelas relativas às obras literárias 
indicadas para o vestibular e representadas por uma ampla produção de estudos e comentários disponíveis no mercado, cuja importância, como auxílio ao leitor, não pode ser desprezada (Disponível em: <http:// www.letras.ufmg.br/atelaeotexto/pesquisaleni.htm>. Acesso em: ....)

Ao serem indicadas, através do vestibular, obras tradicionais e não tradicionais, evita-se o foco exclusivamente nos cânones literários que transformam a Literatura em objeto de culto de um grupo restrito de escritores, imobilizando-se os textos a critérios arbitrários. Assim, as questôes que avaliam essas obras indicadas abrem-se ao fazer literário, valorizando aspectos da contemporaneidade, em que os signos se dobram sob a interação com o leitor e com o escritor, para produzir a transitoriedade dos sentidos.

\section{Avaliação de resultados das provas de múltipla escolha}

O grau de dificuldade das questôes da prova da múltipla escolha é mensurado, tomando-se por base o percentual de acerto dos candidatos que fazem a prova de LPLB. Considera-se muito difícil a questão que obteve percentual de acerto entre zero a vinte por cento do número total de candidatos que se submeteu ao exame; difícil, entre 21 a 40 por cento; médio, entre 41 a 60 por cento; fácil de 61 a 80 por cento e muito fácil entre 81 a 100 por cento, conforme o QUADRO 2, a seguir.

\section{QUADRO 2}

Grau de dificuldade das questôes da prova de Língua Portuguesa e Literatura Brasileira - $1^{\text {a }}$ etapa do Vestibular / UFMG

\begin{tabular}{l|l}
\hline Grau de dificuldade & Percentual \\
\hline Muito Fácil & 81 a 100 \\
Fácil & 61 a 80 \\
Médio & 41 a 60 \\
Difícil & 21 a 40 \\
Muito Difícil & 0 a 20 \\
\hline
\end{tabular}

De 2000 a 2009, os resultados dos candidatos nas provas de Língua Portuguesa e Literatura Brasileira da $1^{a}$ etapa do Vestibular têm apontado para um gráfico equilibrado como o GRAF. 1, a seguir. 


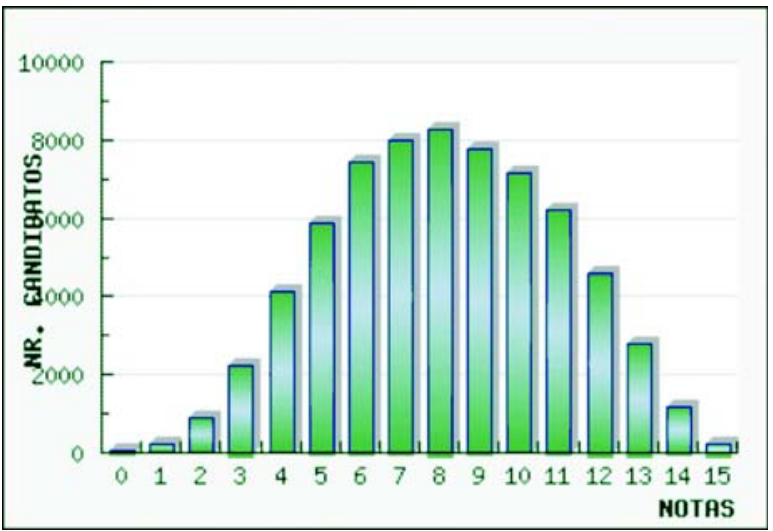

GRÁFICO 1 - Resultado geral dos candidatos na prova de Língua Portuguesa e Literatura Brasileira - $1^{\text {a }}$ etapa do vestibular UFMG/2004

Em 2004, prestaram o exame: 66.915 candidatos. A nota média (\%) foi 53.96, sendo o desvio (\%) de19,04. Em 2006, fizeram a prova 61.233 candidatos. A nota média (\%) foi de 55,8, sendo o desvio de 16,79. Esses dados comprovam haver uma boa distribuição entre o nível de dificuldade das provas de múltipla escolha de LPLB. Observe-se também, a título de ilustração, o GRAF. 2, que apresenta o resultado da primeira etapa do vestibular da UFMG de2007.

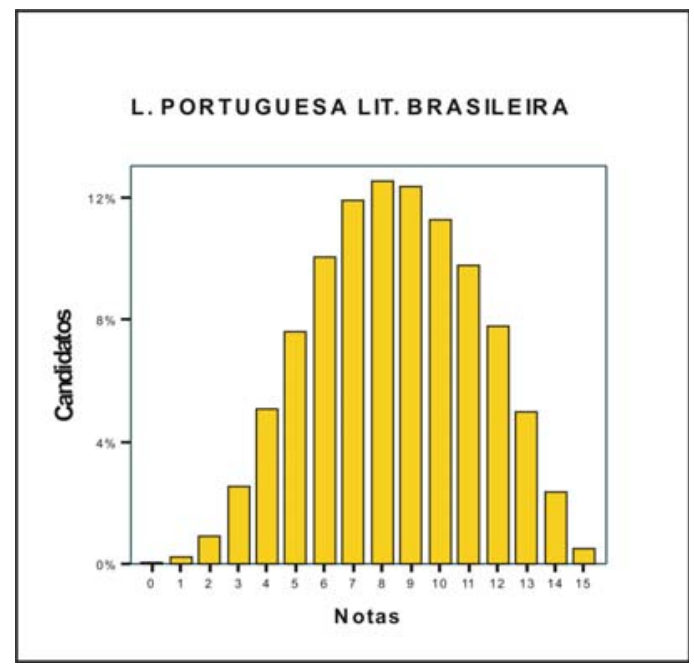

GRÁFICO 2 - Resultado geral dos candidatos na prova de Língua Portuguesa e Literatura Brasileira - $1^{\text {a }}$ etapa do vestibular UFMG/2007 
Em 2007, o total de candidatos foi de 55.799 e a nota média (\%): 56,17 , sendo o desvio (\%) igual a 18,87 . Considerando que eles ainda se encontram em análise, não vamos nos alongar nesse assunto. Passemos adiante

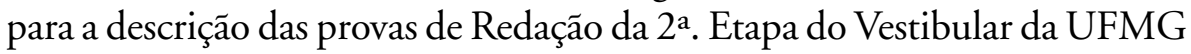
no período de 2000 a 2009.

\section{Redação: uma prova de leitura e escrita}

$\mathrm{Na}$ segunda etapa do concurso vestibular da UFMG, as questões são, preferencialmente, discursivas. As normas específicas para essa etapa do concurso preveem a escolha de conteúdos estimulantes, que impliquem a demonstração da capacidade de lidar com fatos - interpretar, analisar, sintetizar e relacionar, entre outros -, em vez de simplesmente recordá-los e enunciá-los. Dessa forma, nas provas de Redação, são selecionados textos que favoreçam a motivação do candidato em relação a um determinado tema sobre o qual deverá refletir para produzir o seu texto. Nos últimos anos, tem sido sugerida uma grande diversidade de gêneros textuais tanto para a leitura quanto para a produção escrita nas provas de Redação.

Segundo Dell'Isola (2009), nas provas de Redação do Vestibular da UFMG, os enunciados não exigem interpretações sofisticadas dos textos para leitura. Procura-se operar com temas acessíveis ao conjunto dos concorrentes e são propostas atividades de interpretação fundadas na consideração dos elementos linguísticos do texto, nas circunstâncias de sua produção e circulação, no seu diálogo com outros textos. A prova de Redação destina-se a candidatos com a experiência de um jovem recém-saído do Ensino Médio.

De 2000 a 2007, para a Prova de Redação, foi adotado um formato de avaliação que consistia em se avaliar a execução de 6 (seis) propostas de produção escrita, sendo, três questóes baseadas em textos temáticos para leitura e para a redação e três questóes baseadas nas leituras das obras literárias indicadas. Cada prova era composta de questôes às quais o candidato deve responder no espaço de 10 a 12 linhas aproximadamente. Era apresentado um ou mais texto, a ser lido pelo candidato, seguido de uma proposta de escrita.

A partir do vestibular de 2008, houve uma mudança nesse formato da prova de Redação. A comissão elaboradora da prova de redação decidiu reduzir a duas propostas de produção escrita. Assim, nessa prova passou-se a se exigir a produção de dois textos, com média de 25 linhas, um voltado para a análise e a exploração de algum tema contemporâneo / geral e outro voltado para o estudo das obras literárias indicadas pela Comissão. Conforme lembra Xavier 
(2007), essa mudança não rompe com o modelo de escrita já vigente ao longo do trabalho escolar com textos. As propostas de redação partem da leitura de um texto ou de um fragmento de texto com vistas a produção de um gênero textual específico. A avaliação das respostas normalmente leva em consideração dois grandes aspectos: a leitura e a produção de textos. A resposta redigida pelo candidato deve revelar que ele compreendeu o enunciado e, se for o caso, o(s) texto(s) apresentado(s) para a leitura.

\section{A diversidade de gêneros textuais presente nos exames}

É grande a variedade de gêneros textuais dos textos para leitura que servem de base para cada proposta de redação nas provas da UFMG. Nesses últimos dez anos, o formato da prova de redação segue alguns padrōes. Vamos nos concentrar em três tendências:

- apresentação, para a leitura, de dois ou mais textos de diferentes gêneros com um único foco temático, uma mesma tônica argumentativa e mesmo ponto de vista;

- apresentação, para a leitura, de dois ou mais textos de diferentes gêneros textuais com a mesma base temática, mas com diferentes pontos de vista;

- apresentação, para a leitura, de um (ou mais textos) de um mesmo gênero, a partir do qual

- será explorada sua composição por ser um texto linguisticamente produzido em uma variante diferente da escrita da norma padrão ou

- será solicitada a produção de um outro gênero textual a partir do texto de base.

O primeiro consiste na apresentação de mais de um gênero textual em uma mesma questão, com um foco temático, e solicita-se do candidato a produção de um texto sobre o assunto tratado nesses textos lidos. Por exemplo, na prova de 2001, a primeira questão apresenta 3 (três) trechos, 1 (um) extraído de texto teórico sobre a linguagem dos idosos, 1 (um) extraído de artigo jornalístico e 1 (um) depoimento de uma pessoa idosa em condições de extrema miséria física, existencial e moral. Todos os trechos focalizam o fato de os mais idosos serem excluídos de nossa sociedade. No enunciado dessa questão, solicitou-se ao candidato, tendo em vista os três textos, que redigisse uma dissertação que enfocasse o tema "Discriminação dos velhos no Brasil". Esperavase que o candidato fosse capaz de redigir, com suas palavras, um texto articulando 
os 3 trechos lidos. Para isso, deveria identificar o que há de comum entre eles, deixando clara a sua posição sobre o processo discriminatório por que passam os idosos, sem transcrever fragmentos dos trechos lidos. Por meio desta proposta de texto, priorizava-se a produção escrita em que o candidato relacionasse os dois primeiros textos ao terceiro, fragmento do Jornal do Brasil, em que o depoimento de uma pessoa idosa explica e comprova os outros dois textos.

De maneira geral, essa questão suscita, a partir da leitura de textos jornalísticos e literários, a reflexão sobre assuntos pertinentes à história, à cultura e à sociedade brasileira, e tem como objetivo verificar a capacidade dos candidatos de compreender textos informativos de circulação nacional, identificando o enunciador e seu ponto de vista, contrapondo-o com outros textos. A questão requer dos candidatos a reflexão sobre o processo discriminatório que atinge os idosos no Brasil. Por se tratar de um tema atual, contextualizado e amplamente discutido pela mídia e por meios escolares, políticos, e socioculturais diversificados, esperava-se que o tema desencadeasse um grande investimento discursivo e emocional dos candidatos, o que pôde ser observado e objetivamente avaliado pelo desempenho que a maioria obteve na elaboração da respostas.

O segundo formato que passou a ser uma tendência de exploração de texto nas propostas de redação da UFMG consiste na apresentação de dois ou mais textos (geralmente de mais de um gênero textual) de mesma base temática, mas com opiniōes diferentes para serem lidos e partir dos quais o candidato terá que opinar. Por exemplo: em uma das propostas de redação do vestibular da UFMG pediu-se a redação de um texto argumentativo em que o candidato defendesse o ponto de vista apresentado pelos autores dos dois textos: um artigo escrito por Mário Cortella publicado na Folha de São Paulo e uma tirinha de Laerte.

No artigo, Cortella deixa claro que é contra a correria do dia-a-dia, ao contrário dos quadrinhos de Laerte, que, numa primeira leitura, podem dar a impressão de que é preciso ter pressa para ser bem-sucedido. O elemento dificultador dessa questão é a duplicidade de sentidos dos quadrinhos. Numa primeira leitura, eles podem aparentar uma posição favorável à correria (e, nesse caso, se oporia à de Cortella), mas o candidato deveria perceber a ironia que Laerte usa em seus quadrinhos para mostrar o ritmo alucinante que a informática imprime à sociedade, uma vez que as novidades rapidamente são sucateadas, criticando, na verdade, a correria da vida moderna. O enunciado dessa questão deu ao candidato a direção tanto da leitura dos textos quanto do texto argumentativo que deveria escrever. Esperava-se que, além dos elementos 
apresentados como argumentos nos dois textos, ele usasse também elementos da sua experiência de vida para sustentar sua argumentação.

Essa questão exigiu dos candidatos uma reflexão sobre os aspectos negativos do acelerado cotidiano do homem moderno. Além disso, demandou maturidade por parte dos leitores no que se refere à capacidade de ler e interpretar diferentes tipos de texto, inferindo relações não-explícitas entre eles. Na resposta dessa questão, os alunos deveriam: perceber a crítica dos autores e explicitar claramente seu posicionamento favorável à posição defendida pelos autores, argumentando coerentemente. Esperava-se na resposta a essa questão que o candidato explicitasse a crítica dos dois autores à pressa excessiva do homem moderno e argumentasse contra ela. Os candidatos que não se posicionaram claramente ou se posicionaram a favor da pressa demonstraram não ter compreendido bem a questão ou os textos, deixando, portanto, de cumprir total ou parcialmente a tarefa proposta.

O terceiro formato valoriza a norma padrão escrita ou focaliza a produção de um gênero. Geralmente é apresentado apenas um texto a partir a partir do qual se propóe a análise linguística ou a composição de um novo texto. No primeiro caso, por meio da leitura de um trecho escrito em outra variedade linguística, espera-se que o candidato identifique os pontos em que predominam formas dialetais diferentes da norma padrão escrita da língua e redija a respeito das diferenças ou retextualize o texto passando de uma a outra variante. Por exemplo, em uma das propostas de redação explorou-se a escrita de Carolina de Jesus em seu livro Quarto de Despejo. A primeira informação dada na prova, ao candidato, foi a de que esse livro, na época em que foi publicado, gerou muita polêmica em relação a sua autoria. Houve mesmo quem afirmasse que se tratava de um golpe publicitário arquitetado pelo repórter Audálio Dantas. O trecho selecionado para esta questão, extraído do livro, distancia-se da escrita que se espera de um adulto que teve de abandonar a escola no segundo ano primário.

Nessa questão esperava-se que o candidato apontasse os elementos do trecho, retirado do livro, que fazem com que o texto de Carolina Maria de Jesus demonstrasse domínio da linguagem escrita padrão. Para resolver essa questão, o candidato deveria mostrar capacidade de distinguir os elementos mais característicos da linguagem escrita daqueles que podem ser encontrados tanto na escrita quanto na oralidade. Além disso, deveria reconhecer as marcas de oralidade presentes no texto, apontando como resposta para essa questão elementos como: 
- uso de pronomes mais encontrados na escrita do que na oralidade como nos casos de 'quebrar-se', 'espancá-la', 'deu-lhe', 'deu-me', 'impedi-lo' (mesmo que o pronome esteja sendo usado pela autora de forma não-padrão);

- uso de vocabulário e expressões até certo ponto mais sofisticados que os que se espera de uma favelada, como 'imprecionei', 'alterando', 'a notícia circulou';

- uso de tempos verbais mais comuns na escrita e pouco usados na fala, como 'havia deixado';

- uso de metáforas, que dá ao texto um ar poético, como 'O meu coração parecia mola de um trem em movimento', 'estou acostumada com os espetáculos que ele representa’;

- uso de concordância verbal e nominal de acordo com a norma culta;

- elaboração de períodos coesos, percebida por meio de articuladores;

- opção por uma tipologia textual de determinada espécie (diário).

Esperava-se que essa questão levasse o candidato a refletir sobre o uso da língua, as diferenças entre registros. O candidato deveria, não só identificar, pelo menos três dos elementos linguísticos que se distanciavam dos esperados de um adulto que não frequentou a escola formal, mas, além disso, ser capaz de justificar sua escolha num texto coeso e bem estruturado.

No segundo caso - o de se apresentar um texto para se propor a produção de um gênero - é comum a integração entre ambos: o texto a ser lido e o a ser redigido. Por exemplo, no vestibular de 2007, foi apresentada uma

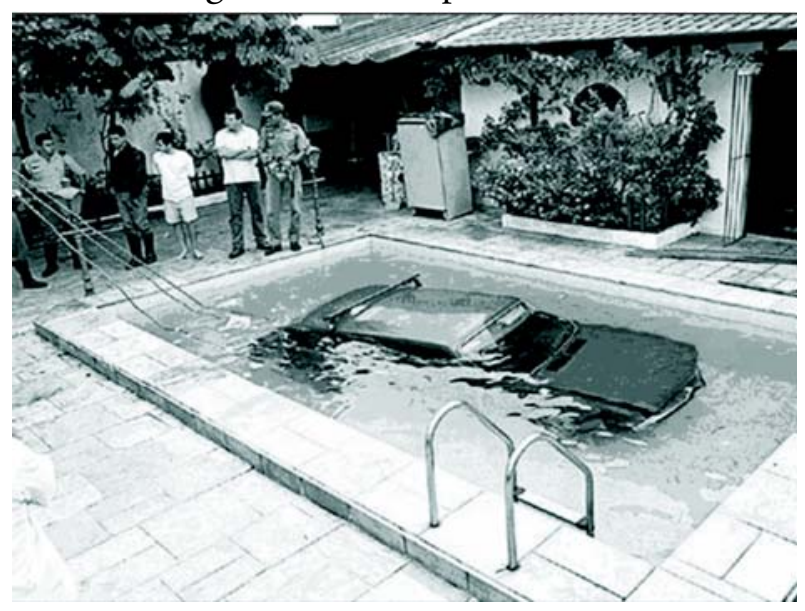
foto ao candidato. Solicitou-se que o candidato observasse esta imagem:

Disponível em: <http://www.solbrilhando.com.br/_Slides/_Diversos/ agua_no_carburador.pps>. Acesso: 10 maio 2006. 
Esperava-se que o candidato inicialmente observasse os detalhes da foto que poderiam ser usados numa notícia. Em seguida, situando-se no papel de um repórter, ele deveria atrair a atenção do leitor para a excepcionalidade da cena. Uma frase que sintetizasse o ocorrido poderia ser elaborada como tópico da notícia. No desenvolvimento do texto, ele deveria imaginar aquilo que o leitor gostaria de saber sobre o fato.

Algumas perguntas são fundamentais nesse sentido: a) As circunstâncias do fato (Onde ocorreu o fato? Quando ocorreu a queda do carro na piscina? Como ocorreu o fato? Quem eram os envolvidos?); b) As razóes do fato (Por que o carro estaria na piscina? Ele foi jogado lá? Foi uma questão de imperícia do motorista?); c) As consequências do fato (Que efeitos foram gerados com o ocorrido? Houve prejuízos materiais? Alguém ficou em estado de choque ao ver a cena?); d) As ações decorrentes do fato (Que providências foram tomadas frente ao ocorrido? O corpo de bombeiros foi chamado? Acionaram a polícia?). $\mathrm{O}$ texto deveria ser objetivo e sucinto no levantamento dos aspectos que teriam feito do acontecimento algo inusitado e, portanto, objeto de uma matéria jornalística. Avaliou-se a adequação ao tema: o texto deveria abordar um aspecto relativo à presença de um carro na piscina; a adequação ao objetivo da questão: configuração de uma "notícia". Certamente, não se exigiu os parâmetros especificamente empregados por profissionais do jornalismo, mas uma configuração textual mínima que demonstrasse habilidade na apresentação escrita de um fato. Quanto ao desenvolvimento, foram avaliados os componentes do fato (circunstâncias, razões, consequências, etc), tendo em vista uma ordem de desenvolvimento compatível com a posição de um repórter que colhe informaçôes ao chegar ao local após o acontecimento. Além da coerência, avaliou-se o uso adequado dos recursos de coesão entre as frases do texto, bem como cumprimento aos requisitos gramaticais, ortográficos e de pontuação, que norteiam o texto escrito.

Segundo Bianchet et alli (2007), "se foi pedido ao candidato que argumente contra as idéias defendidas pelo autor num determinado texto, é imprescindível que ele deixe claro qual é a idéia defendida e que levante argumentos contra a tese nele apresentada." O candidato deve revelar que é capaz de compreender o enunciado da questão, bem como os textos que a compõem, evidenciando ser um bom leitor.

Na prova de Redação, observam-se nos textos produzidos pelos candidatos a pertinência e a consistência dos argumentos empregados, a adequação vocabular, assim como a eficácia de outros recursos com relação aos 
objetivos propostos. São particularmente verificadas: 1) a compreensão do enunciado da questão e 2) a adequação do texto produzido a esse enunciado. Em outras palavras, procura-se verificar se o candidato atendeu com precisão ao que lhe foi solicitado.

\section{O que provam as provas de seleção da UFMG}

O processo de formação acadêmica requer do estudante habilidades práticas no uso da língua. O texto é a unidade significativa que concretiza as competências e habilidades linguísticas relacionadas a situações concretas. $\mathrm{O}$ concurso vestibular deve selecionar o candidato que evidencia estar apto para ingressar no Ensino Superior, que demonstre ser capaz de frequentar, com proveito, os cursos de formação profissional que a universidade oferece. A prova de língua portuguesa e literatura brasileira e a de redação avaliam a leitura e produção escrita para a admissão dos candidatos nos cursos de graduação.

Assim como todo processo seletivo para o ingresso em curso superior, o da UFMG deve ser justo e transparente. Baseadas nesse pressuposto, as equipes de elaboração das provas de Língua Portuguesa e Literatura Brasileira da Comissão Permanente do Vestibular (COPEVE) oferecem, todos os anos, uma publicação das provas comentadas ao público interessado nas concepções e critérios que servem de parâmetro para a realização dessas provas. Essas equipes reconhecem que, ainda que não sejam igualitárias as condições de disputa pelas vagas dos cursos universitários, é possível minimizar essa desigualdade, divulgando-se amplamente, para os vestibulandos que desejam complementar sua preparação para o Concurso Vestibular, obras com as provas comentadas pela comissão elaboradora das provas.

As provas de Língua Portuguesa e Literatura Brasileira e de Redação do vestibular da UFMG estão disponíveis pela Comissão Permanente do Vestibular (COPEVE) no site www.ufmg.br/copeve/site e os cadernos de provas resolvidas e comentadas pelas equipes de elaboração encontram-se disponíveis em fascículos que reúnem as provas de $1^{\mathrm{a}} \mathrm{e} 2^{\mathrm{a}}$ etapas, publicados pela Editora da UFMG (www.editoraufmg.com.br).

Em respeito a esse público, as equipes de elaboração das provas se empenham em publicar essas obras que constituem verdadeiros documentos que registram a intenção de tornar mais democrático esse processo seletivo. Por isso, na busca permanente pela qualidade, as equipes estão abertas a críticas e comentários que visem a contribuir para o aperfeiçoamento dos trabalhos. 
As diretrizes específicas que regulamentam a elaboração das questôes das provas dos Vestibulares da UFMG encontram-se nas normas gerais da COPEVE, vigentes desde março de 1996. Os critérios de seleção são discutidos pela Equipe, antes da elaboração das provas, levando-se em consideração os programas do Ensino Fundamental e Médio e sua pertinência em relação aos cursos de Ensino Superior.

\section{Palavras finais}

A análise realizada nesta pesquisa nos leva a concluir que as provas de LPLB e de Redação do Vestibular da UFMG nos últimos dez anos exigem dos candidatos o domínio da norma padrão escrita, variante adequada às situações de interação verbal mais frequentes na convivência acadêmica e profissional. Essas provas também avaliam a qualidade da compreensão leitora e da expressão escrita desse candidato. As questôes de múltipla escolha exigem que os candidatos localizem e organizem as informações textuais e a elas relacionadas, inferindo quais informações no texto são relevantes e lidando com conceitos contra-intuitivos. Eles são levados a demonstrar entendimento completo e detalhado de textos cujos conteúdos ou forma são próximos aos dos textos acadêmicos e são conduzidos a avaliar criticamente ou construir hipóteses a partir de conhecimento específico.

Em relação à prova de Redação, constatou-se que o candidato não só deve demonstrar ter domínio da norma padrão da língua, como também deverá ser um leitor capaz de compreender plenamente a proposta de redação e de aplicar conceitos das várias áreas de conhecimento para desenvolver o tema, dentro dos limites estruturais de um texto, geralmente, argumentativo. Almeja-se a classificação de um candidato que seja capaz de selecionar, relacionar e interpretar informaçôes, fatos, opiniōes e argumentos em defesa de um ponto de vista e de demonstrar conhecimento dos mecanismos linguísticos necessários para a construção da argumentação, mostrando respeito aos valores humanos e à diversidade sociocultural.

A compreensão do tema envolve a articulação de diferentes perspectivas para defesa de um ponto de vista; a informatividade; a utilização de conceitos de várias áreas; o emprego de citaçôes, alusōes, analogias, exemplificações, dados e informaçóes. A estrutura requer a composição de um texto com introdução, desenvolvimento, conclusão; o encadeamento e progressão temática. Além da coerência, devem ser consideradas a coesão lexical (uso dos sinônimos, hiperônimos, repetição, reiteração, dentre outros) e a coesão 
gramatical: (uso de conectivos, tempos verbais, pontuação, sequência temporal, relações anafóricas, conectores intersentenciais, interparágrafos, intervocabulares, dentre outros).

Constatou-se que as propostas de redação da UFMG de 2000 a 2009 foram de fato elaboradas a fim de se verificar a capacidade dos candidatos de produzir textos coesos, bem articulados, com consistência de argumentação, adequados à situação comunicativa proposta, além de avaliar sua capacidade de leitura. Para redigir, os candidatos devem compreender os textos ou os trechos apresentados em cada uma das questóes, usados como estímulo, identificando a ideia central, percebendo as ideias implícitas, assim como certos recursos discursivos - como o uso de ironias e de metáforas, por exemplo -, reconhecendo as vozes neles presentes, posicionando-se criticamente em relação ao que é defendido ou apresentado pelos autores por intermédio dos textos.

Em suma, as provas do vestibular da UFMG, nos últimos dez anos não avaliam apenas a capacidade de leitura e interpretação textual dos candidatos, objetivam também analisar as habilidades cognitivas relacionadas com a leitura e de escrita por meio da sua redação. Espera-se que, além de comprovar sua habilidade de leitura, os candidatos se expressem, por escrito, empregando adequadamente o padrão culto escrito do Português e procurando compor um texto em que suas ideias sejam apresentadas da melhor maneira possível. Não há dúvida de que cumprem sua função, as provas do exame de seleção vestibular dessa universidade.

\section{Referências}

BIANCHET, Sandra et alli. Lingua Portuguesa e literatura brasileira no vestibular 2005 - provas resolvidas e comentadas. Belo Horizonte: Ed. UFMG, 2005. $74 \mathrm{p}$.

BIANCHET, Sandra et alli. Lingua Portuguesa e Literatura Brasileira no vestibular 2006. Belo Horizonte: Editora UFMG, 2006. 68 p.

BIANCHET, Sandra et alli. Lingua Portuguesa e Literatura Brasileira no vestibular 2007. Belo Horizonte: Editora UFMG, 2007. 76 p.

DELL'ISOLA, Regina L. P. O ENEM e o Vestibular na berlinda. 2009. No prelo. DELL'ISOLA, Regina L. P. et alli. Lingua Portuguesa e literatura brasileira no vestibular: provas do Vestibular 2001 resolvidas e comentadas. Belo Horizonte: Ed. UFMG, 2001. 
DELL'ISOLA, Regina L. P. et alli. Lingua Portuguesa e literatura brasileira no vestibular: provas do Vestibular 2002 resolvidas e comentadas. Belo Horizonte: Ed. UFMG, 2002.

DELL'ISOLA, Regina L. P. et alli. Lingua Portuguesa e Literatura Brasileira no vestibular 2003: provas e comentários. Belo Horizonte: Editora UFMG, 2003. $70 \mathrm{p}$.

DELL'ISOLA, Regina L. P. et alli. Lingua Portuguesa e Literatura Brasileira no vestibular 2004: provas e comentários. Belo Horizonte: Editora UFMG, 2003. $66 \mathrm{p}$.

MIRANDA, José Américo et alli. Lingua Portuguesa e Literatura Brasileira no Vestibular 2008 - provas do vestibular - resolvidas e comentadas. Belo Horizonte: Editora UFMG, 2009. 68 p.

NASCIMENTO, Edson; COSTA VAL, M.Graça et alli. Lingua Portuguesa e Literatura Brasileira no Vestibular: provas e comentários. Belo Horizonte: Ed. UFMG, 1999.

OLIVEIRA, Leni. Canonização: manutenção e aplauso. Disponível em: <http://www.letras.ufmg.br/ atelaeotexto/pesquisaleni.htm>. 2008

XAVIER, Joelma Rezende. O interacionismo sociodiscursivo em análises de produçóes de texto no processo seletivo de vestibular. Dissertação (Mestrado) - UFMG Disponível em: <http://www.dominiopublico.gov.br/pesquisa $>$.

XAVIER, Joelma Rezende. Redação na UFMG. Estado de Minas, Caderno D+, 18 dez. 2007.

Recebido em outubro de 2009. Aprovado em janeiro de 2010. 